\title{
Driving and visual deficits in stroke patients
}

\author{
Direção de automóveis e déficits visuais em pacientes com AVC \\ Marina Marcondes Braga', Renato Nickel', Marcos Lange', Élcio Juliato Piovesan²
}

\begin{abstract}
Objective: The aim of the present study was to conduct an exploratory assessment of visual impairment following stroke, and to discuss the possibilities of reintroducing patients to the activity of driving. Methods: The Useful Field of View test was used to assess visual processing and visual attention. Results: A total of 18 patients were included in the study, and were assigned to either the drive group ( $n=9)$ or the intention group $(n=9)$. In the drive group, one patient was categorized as moderate-to-high risk; whereas, in the intention group, one patient was categorized as low-to-moderate risk. Additionally, two patients in the intention group were categorized as high risk. The patients did not perceive their visual deficits as a limitation. Conclusion: Visual attention is an interference factor in terms of the safe performance of driving after a stroke. All patients showed a high level of interest for the independence provided through being able to drive.
\end{abstract}

Keywords: stroke; automobile driving; accidents, traffic.

\section{RESUMO}

Objetivo: O objeto deste estudo foi realizar uma avaliação exploratória de déficits visuais decorrentes do AVC e discutir possibilidades de retorno à direção de automóveis. Métodos: Estudo descritivo e observacional. O software UFOV foi utilizado para avaliar o processamento visual e atenção visual. Resultados: Um total de 18 pacientes foram incluídos no estudo, classificados em Grupo Direção - GD ( $n=9$ ) e Grupo Pretensão - GP ( $n=9)$. No GD, um paciente foi classificado em moderado a alto risco de acidentes, e um paciente do GP em baixo a moderado risco. Especificamente, no grupo GP, dois pacientes foram classificados em alto risco de acidentes. Pacientes não reconhecem os déficits visuais como dificuldades. Conclusão: Atenção visual é um fator de interferência no desempenho seguro da direção após o AVC. Todos os pacientes mostraram alto interesse na independência oferecida pela direção de automóveis.

Palavras-chave: acidente vascular cerebral; condução de veículo; acidentes de trânsito.

A significant proportion of stroke patients face limitations in their daily activities, including the ability to drive. Driving is crucial as it enables the patient to be independent, as well as maintain social relationships and find work opportunities ${ }^{1,2,3,4}$.

Once it has been deduced preliminarily that driving may be unsafe for stroke patients, it is necessary that a multidisciplinary team evaluate the patient. This is to guarantee personal and society safety, as well as to allow a better chance of a safe return to driving. Worldwide, studies suggest that $95 \%$ of individuals who undergo team assessments feel that it is safe to return to driving ${ }^{5}$.

The aim of this study was to conduct an exploratory assessment of visual impairment and to discuss the possibilities of returning to driving, following stroke.

\section{METHODS}

This was a descriptive and observational study that focused on patients with chronic stroke. The study was conducted at the Cerebrovascular Outpatient Clinic of the Hospital Clinics of the Federal University of Paraná between July 2015 and March 2016. The research project was approved by the Local Research Ethics Committee under registration number 19838413.9.0000.0102 and reference $n^{\circ} 362.725$ on August 16, 2013. The elaboration of this article was guided by the protocol of the Strengthening the Reporting of Observational Studies in Epidemiology statement.

Chronic (more than three months) stroke patients between 18 to 60 years of age, who drove before the occurrence of stroke, participated in the current study. Patients were excluded if they had other health conditions that could limit their performance.

All patients were submitted to the Useful Field of View (UFOV) test to assess visual function and visual attention capabilities, both of which are considered predictive tools for assessing the ability to perform the activity of driving after the occurrence of stroke. The UFOV consists of three sub-tests: 1) processing speed and the central vision test, 2) divided attention,

${ }^{1}$ Universidade Federal do Paraná, Hospital de Clínicas, Terapia Ocupacional, Curitiba PR, Brasil;

${ }^{2}$ Universidade Federal do Paraná, Curitiba PR, Brasil.

Correspondence: Renato Nickel; Universidade Federal do Paraná, Campus Botânico | Bloco Didático II; Av. Prefeito Lothário Meissner, 632; $80210-170$ Curitiba PR, Brasil; E-mail: renatonickel@hotmail.com.

Conflict of interest: There is no conflict of interest to declare.

Received 13 June 2017; Received in final form 01 September 2017; Accepted 31 October 2017. 
and 3) selective attention. The first test assesses the speed of visual processing in increasingly complex task demands, and it is necessary to use both eyes to detect, identify, and localize briefly-presented targets. The second test assesses divided attention and is necessary to identify the target and localize a simultaneously-presented target displayed on the periphery of the monitor. The third test is identical to the second test, except that the target is embedded in distractors, making the task more difficult. This task assesses selective attention ${ }^{6,7,8,9}$.

The results are presented in scores, reported in milliseconds (ms), for each of the three subtests. The final result is a combination of the results of the three subtests and is automatically calculated by the software. It determines the risk of a car crash, categorized into different risk levels (very low risk, low risk, lowto-moderate risk, moderate-to-high risk and high risk) ${ }^{8}$.

The statistical analyses were conducted using the non-parametric Mann-Whitney U test for comparison of the unpaired groups and evaluation of the degree of data interlacing. For the UFOV test, the null hypothesis was accepted at $\mathrm{p}<0.05$.

Patients were divided into two groups to deduce the correlation between the decision of the patient to return to driving and the probability of their involvement in a car accident, considering the visual deficits of the patient as a result of the stroke. The drive group (DG) comprised patients who returned to driving after stroke, and the intention group (IG) comprised patients who intended to return to driving.

\section{RESULTS}

A total of 30 patients were selected during the study period; however, only 18 met all the inclusion criteria. The mean age of patients was $42.2 \pm 12.5$ years, and eight of the participants were female. Considering the general UFOV results in terms of the risk of a car accident, of the $12(66.6 \%)$ patients who were categorized as very low risk, half had returned to driving (DG). Two patients were categorized as low risk, and both had returned to driving (DG). One patient was categorized as moderate-to-high risk and he had already returned to driving (DG). Only one patient was categorized as low-to-moderate risk (IG) and he intended to return to driving. The last two patients were categorized as high risk, and neither returned to driving (IG). Tables 1 and 2 summarize these data.

Nine patients were included in each group. The mean age was $40.2 \pm 11.8$ years in the DG and $44.1 \pm 13.6$ years $(p=$ $0.605)$ in the IG. The study evaluation was conducted $170 \pm$ 294 days after stroke; $261.2 \pm 402.2$ days later in the DG, and $79.2 \pm 57$ days following stroke in the IG $(p=0.340)$. In both groups, four patients were female. Ischemic stroke was the etiology in seven patients in the DG and five patients in the IG. In terms of educational level, two patients in the DG, and three patients in the IG had a bachelor's degree ( $p=0.501)$. Considering employee status, six patients in the DG and three in the IG were employed $(p=0.267)$.
Table 1. Individual results for the UFOV test.

\begin{tabular}{|c|c|c|c|c|c|}
\hline Patient & Group & Risk & $\begin{array}{l}\text { Processing } \\
\text { speed and } \\
\text { central vision }\end{array}$ & $\begin{array}{l}\text { Divided } \\
\text { attention }\end{array}$ & $\begin{array}{l}\text { Selective } \\
\text { attention }\end{array}$ \\
\hline P1 & IG & Very low & 17.4 & 34.9 & 141.6 \\
\hline P2 & IG & Very low & 18.4 & 31.5 & 34.9 \\
\hline P3 & $D G$ & Very low & 17.7 & 18.2 & 215.0 \\
\hline P4 & IG & Very low & 14.8 & 75.5 & 78.2 \\
\hline P5 & $D G$ & Very low & 17 & 17 & 211.6 \\
\hline P6 & IG & Very low & 14.9 & 23 & 58.2 \\
\hline P7 & $D G$ & Very low & 14.8 & 17.2 & 111.5 \\
\hline P8 & IG & High & 71.5 & 371.6 & 500 \\
\hline P9 & $D G$ & Very low & 14.8 & 38 & 91 \\
\hline P10 & $D G$ & Low & 14.8 & 218 & 218 \\
\hline P11 & $D G$ & Very low & 14.8 & 14.8 & 101.5 \\
\hline P12 & IG & High & 71.5 & 500 & 500 \\
\hline P13 & IG & Very low & 14.8 & 14.9 & 51.5 \\
\hline P14 & $D G$ & $\begin{array}{c}\text { Moderate-to- } \\
\text { high }\end{array}$ & 14 & 500 & 500 \\
\hline P15 & IG & Very low & 14.8 & 48.2 & 48.2 \\
\hline P16 & IG & $\begin{array}{l}\text { Low-to- } \\
\text { moderate }\end{array}$ & 28.2 & 264.9 & 441.6 \\
\hline P17 & $D G$ & Very low & 14 & 18 & 28 \\
\hline P18 & $D G$ & Low & 14.8 & 118.2 & 118.2 \\
\hline
\end{tabular}

DG: drive group; IG: intention group.

Table 2. Risk for driving in the Drive Group (DG) and the Intention Group (IG).

\begin{tabular}{lcc}
\hline Risk* & IG & DG \\
\hline Very low & 6 & 6 \\
Low & 0 & 2 \\
Low-to-moderate & 1 & 0 \\
Moderate-to-high & 0 & 1 \\
High & 2 & 0 \\
\hline${ }^{*}=0.46$, Mann Whitney-U Test & &
\end{tabular}

All patients in the DG had central vision and the normal processing speed was preserved; however, two faced difficulties of divided attention and one had severe difficulty in terms of divided attention. In terms of selective attention, only one patient faced a severe difficulty. Table 1 summarizes the results of the UFOV test in both groups.

One patient from the DG (P14), who presented with a moderate-to-high car accident risk, considered poor vision to be a limitation that discouraged driving. Two other patients (P5 and P10) stated that poor vision was a difficulty while driving, although no significant results were shown in the UFOV test. Only two patients (P11 and P14) were evaluated by the national traffic department. Although they were allowed to drive, we observed that P14 showed a considerable visual deficit. 
Two patients in the IG had central vision loss and a decrease in processing speed, one had difficulty with divided attention and one had severe difficulty with divided attention. In terms of selective attention, three presented with severe difficulty. Table 1 summarizes the results of the UFOV test in both groups.

Patients in the IG who were categorized as high or low-to-moderate risk mentioned fear and motor skills as a difficulty in being able to return to driving but did not refer to vision as a difficulty that limited them from returning to driving. This shows the divergence of what they consider to be a limitation and what the difficulty actually is. One of the patients in this group (P1) referred to vision as a limitation, although, his results on the UFOV test were categorized as a very low crash risk.

There were no significant differences between the groups when comparing the risk of driving and the results for the three subtests of the UFOV, as seen in Tables 2 and 3. However, the results of participants within the DG were better than those in the IG in terms of processing speed and central vision, divided attention, and selective attention.

\section{DISCUSSION}

In the current study, there was no significant difference between the results obtained from the evaluation of patients who returned to driving and those who did not, following stroke. However, the results of specific abilities such as processing speed, and divided and selective attention were better in participants from the DG.

The results of the present study corroborate results of previous studies that have demonstrated the importance of driving for patients, allowing them to have independence, freedom, and enabling them to expand their social and work-related opportunities ${ }^{1,3,5}$.

This study was based on an international evaluation method for driving rehabilitation, that enabled the identification of an interference factor such as a visual deficit or a motor issue that may hinder the safe driving after the occurrence of stroke. ${ }^{3}$ Similar to our evaluation, $95 \%$ of patients have felt safe returning to driving with a low risk of involvement in traffic accidents ${ }^{2,5,10}$. Apart from this, the reduced risk was based on therapeutic recommendations and indications ${ }^{5,11}$. The present study also demonstrated the divergence between the perception of the patient about his visual
Table 3. Results of the subtests of the UFOV test in the Drive Group (DG) and the Intention Group (IG).

\begin{tabular}{|c|c|c|c|}
\hline Variable* & IG & DG & $\mathrm{P} * \star$ \\
\hline $\begin{array}{l}\text { Processing speed and } \\
\text { central vision }\end{array}$ & $\begin{array}{c}17.4 \\
(48.2-78.2)\end{array}$ & $\begin{array}{c}14.0 \\
(38.0-154.5)\end{array}$ & 0.094 \\
\hline Divided attention & $\begin{array}{c}48.2 \\
(31.5-264.9)\end{array}$ & $\begin{array}{c}38.0 \\
(18.0-75.2)\end{array}$ & 0.161 \\
\hline Selective attention & $\begin{array}{c}78.2 \\
(51.5-441.6)\end{array}$ & $\begin{array}{c}15.5 \\
(218.0-288.5)\end{array}$ & 0.666 \\
\hline
\end{tabular}

function and the objective test, which showed increased risk of accidents. This was because the patient incorrectly felt safe to return to driving, without considering real deficits.

In the present study, two patients were allowed by the national traffic department to return to driving after their stroke, both of whom had significant visual deficits, increasing the risk of a car accident. Although this study involved a small sample, our data highlight errors in the current assessment procedure in Brazil and the importance of specific and sensitive evaluation of visual deficits. Factors such as visual deficits affect safety during driving and, as a result, the risk of a crash cannot be ruled out.

It is important to consider the divergence between what the stroke patients consider a limitation as opposed to the actual difficulty in engaging in the activity. This reflects and reinforces the need for a complete assessment to ensure safety of all people on the road.

Considering these findings, urgent changes need to occur in the official evaluation, including the formation of a multidisciplinary team and the development of standard protocols, as is followed in developed countries ${ }^{1,3,5}$.

One important limitation in the present study is the small sample, as it restricts a more in-depth analysis and discussion about the individuals and the possible correlations between the evaluation carried out and the groups studied. This study only evaluated the visual function of the patients and other functions need to be considered, to reach a final conclusion on the capacity of the patient to return to driving after a stroke.

In conclusion, visual function is an important factor for driving a vehicle after stroke. In Brazil, new guidelines must be established to include a multidisciplinary team and a standard protocol to evaluate the safety of these patients when returning to driving.

\section{References}

1. Petzold A, Korner-Bitensky N, Rochette A, Teasell R, Marshall S, Perrier MJ. Driving poststroke: problem identification, assessment use, and interventions offered by canadian occupational therapists. Top Stroke Rehabil. 2010 Sep-Oct;17(5):371-9. https://doi.org/10.1310/tsr1705-371

2. Tan KM, O'Driscoll A, O'Neill D. Factors affecting return to driving post-stroke. Ir J Med Sci. 2011 Mar;180(1):41-5. https://doi.org/10.1007/s11845-010-0528-9
3. Poole D, Chaudry F, Jay WM. Stroke and driving. Top Stroke Rehabil. 2008 Jan-Feb;15(1):37-41. https://doi.org/10.1310/tsr1501-37

4. Finestone HM, Marshall SC, Rozenberg D, Moussa RC, Hunt L, Greene-Finestone LS. Differences between poststroke drivers and nondrivers: demographic characteristics, medical status, and transportation use. Am J Phys Med Rehabil. 2009 Nov;88(11):904-23. https://doi.org/10.1097/PHM.0b013e3181aa001e 
5. Pearce AM, Smead JM, Cameron ID. Retrospective cohort study of accident outcomes for individuals who have successfully undergone driver assessment following stroke. Aust Occup Ther J. 2012 Feb;59(1):56-62. https://doi.org/10.1111/j.1440-1630.2011.00981.x

6. Edwards JD, Ross LA, Wadley VG, Clay OJ, Crowe M, Roenker DL et al. The useful field of view test: normative data for older adults. Arch Clin Neuropsychol. 2006 May;21(4):275-86. https://doi.org/10.1016/j.acn.2006.03.001

7. Marshall SC, Molnar F, Man-Son-Hing M, Blair R, Brosseau L, Finestone $\mathrm{HM}$ et al. Predictors of driving ability following stroke: a systematic review. Top Stroke Rehabil. 2007 Jan-Feb;14(1):98-114. https://doi.org/10.1310/tsr1401-98
8. Selander H, Johansson K, Lundberg C, Falkmer T. The Nordic stroke driver screening assessment as predictor for the outcome of an on-road test. Scand J Occup Ther. 2010;17(1):10-7. https://doi.org/10.3109/11038120802714898

9. Elgin J, Mcgwin G, Wood JM, Vaphiades MS, Braswll RA, DeCarlo DK et al. Evaluation of on-road driving in people with hemianopia and quadrantanopia. Am J Occup Ther. 2010 Mar-Apr;64(2):268-78. https://doi.org/10.5014/ajot.64.2.268

10. Ponsford AS, Viitanen M, Lundberg C, Johansson K. Assessment of driving after stroke: a pluridisciplinary task. Accid Anal Prev. 2008 Mar;40(2):452-60. https://doi.org/10.1016/j.aap.2007.07.015

11. Akinwuntan AE, Feys H, DeWeerdt W, Pauwels J, Baten G, Strypstein E. Determinants of driving after stroke. Arch Phys Med Rehabil. 2002 Mar;83(3):334-41. https://doi.org/10.1053/apmr.2002.29662 